\title{
Defibrillation Shock Amplitude, Location and Timing
}

\author{
Shimon Rosenheck \\ Hadassah Hebrew University Medical Center, Jerusalem, \\ Israel
}

\section{Introduction}

The only effective treatment of ventricular fibrillation, in both clinical and experimental medicine, is the electrical defibrillation. Although, critical site ablation is feasible in idiopathic ventricular fibrillation (Knecht et al, 2009), the defibrillation still has remained the only evidence based, generally accepted treatment of this arrhythmia (Jacobs et al, 2010; Deakin et al, 2010). Strong evidence supports that external and internal defibrillations can save the life of patient at risk for sudden cardiac death. Several high-risk groups were defined and implantable defibrillators significantly prolonged the life of these patients when compared to the best medical treatment (Maron, 2002; Ezekowitz et al, 2003; Desai et al, 2004; Dalal et al, 2005; Silka et al, 2006; Sacher et al, 2006; Daubert et al, 2007; Rosenheck et al, 2010). However, the majority of sudden cardiac death victims belong to the low-risk groups. For this reason, most of the sudden cardiac death cases cannot be protected with implantable defibrillators (Huikuri et al, 2001). To resolve this paradox, public access defibrillation was suggested in the high-risk locations (Folk et al, 2010; Winkle et al, 2010; Kitamura et al, 2010; Eisenberg et al, 2010; Rho et al, 2011). Moreover, most of the sudden cardiac death cases occur at home, mainly during the early morning hours. Only early defibrillation may save these patients and to achieve it defibrillators will be available in each house. Non-professional persons, who may witness the sudden cardiac death, will operate these home-defibrillators. They cannot verify the success of the intervention and cannot react immediately with a second shock if the fibrillation continues after the first one and the defibrillator will not detect the failure. For this reason, the successful defibrillation with the first shock is even more important and the external defibrillators will be necessarily more reliable and user-friendly (Rosenheck et al, 2009a).

During the last 25 years, a vast amount of information on clinical and experimental defibrillation was accumulated. The experimental data was obtained from the effect of shock on single cell, in small-perfused tissues and whole heart. Until recently, the available methods did not allow imaging of defibrillation in closed chest models. Mathematical simulations contributed to the understanding of ventricular fibrillation mechanism and defibrillation in closed chest models and human subjects.

External and internal factors determine the defibrillation success or failure. Usually, the external factors, like shock amplitude, location and timing may be modified. These factors belong to the physical properties of the defibrillators. A computerized automatic defibrillator has to be flexible, and capable to deliver the most effective defibrillation shock 
when needed. These 3 properties may be integrated and personalized for each individual patient. However, the location and timing are still not used in the available defibrillators. The only controllable parameter, in both internal and external defibrillators, is the amplitude of the delivered shock and it may be unnecessarily very high. The possible combination of these external shock characteristics will be discussed.

It is more difficult to control the internal than the external factors. This is the reason for occasional non-reproducibility of the defibrillation outcome in the same subject with the same shock setting. The propagation of the ventricular fibrillation waveform prior to the defibrillation, the state of depolarization of the myocardium, spiral waves and singularity points or lines are only a few of many known and still unknown factors. These internal determinants will also be discussed and correlated to the above-mentioned external factors.

\section{Shock amplitude - Historical and clinical data}

More than 100 years ago, it was discovered that a shock might terminate ventricular arrhythmias. Already at that time it was understood that only a strong shock might be successful. Many theories were proposed to explain the mechanism of the defibrillation. All these theories offered reason for the need of a high energy for defibrillations. The first theory was proposed by Wiggers and was called the "Total Extinction" hypothesis (Wiggers, 1940). According to it, the energy delivered to the fibrillating heart has to be able to terminate the electrical activity of the whole myocardium, to create a silent period, and to allow the normal rhythm to overtake the electrical activity in the heart muscle. Wiggers sustained that maintaining the fibrillation even in a small mass of myocardium will prevent resumption of the coordinated activity. Although there is a strong logic in this hypothesis and is simple and attractive, future experimental evidences did not support it. First of all, there is no need to terminate the electrical activity in all the myocardial mass. It is enough to defibrillate only a certain amount of the fibrillating myocardium and the arrhythmia in the rest of the myocardium is not enough to continue the fibrillation. This hypothesis is called the "Critical Mass" hypothesis (Zipes et al, 1975). Moreover, it is not enough only to terminate the arrhythmia, but also it is important to avoid reinitiation of the fibrillation (Trayanova et al, 2006). Regardless the hypothesis, only a strong shock can terminate and prevent re-induction of ventricular fibrillation.

\subsection{Defibrillation dose-response curve}

Because the only measurable parameter was the amplitude of the shock, different methods were suggested to correlate the shock energy with the success of the defibrillation. This correlation between the defibrillation energy and the defibrillation success is a sigmoid dose-response curve (Figure 2.1). At a low energy a small percent of the attempts may still be successful and the success rate will increase with stronger shocks. The curve achieves a theoretical plateau at certain energy. As long as the defibrillation was achieved with an external defibrillator under professional human control, this dose response curve had only theoretical and academic importance. With the introduction of implantable automatic defibrillators, the energy had to be programmed from a head, considering the required success rate of $>99 \%$.

In an experimental study, to obtain a dose-response curve, 48 trials had to be performed, during 192 minutes (Davy et al, 1987). Although this method is the most reliable to determine the safe programmed energy, it is not acceptable for clinical evaluation. After 
induction of ventricular fibrillation, either intra-operative or at a latter test of the defibrillation threshold, repeated tests each one with a lower shock-energy are performed. The testing is stopped when the defibrillation fails and the last successful defibrillation energy is considered the defibrillation threshold. In experimental models this energy will be able to defibrillate only $50 \%-75 \%$ of the episodes. The safe energy to program the first shock of the automatic defibrillator is the plateau energy and this is achieved by doubling the threshold energy. The desired clinical test is shown in Figure 2.2, but the practiced clinical protocols are shown in Figure 2.3. These tests were used during the last 20 years. Today, because the big gap between the threshold and the device capacity, the number of shocks used for the test is reduced to minimum and even it is seriously questioned (Higgins et al, 2005; Viskin \& Rosso, 2008).

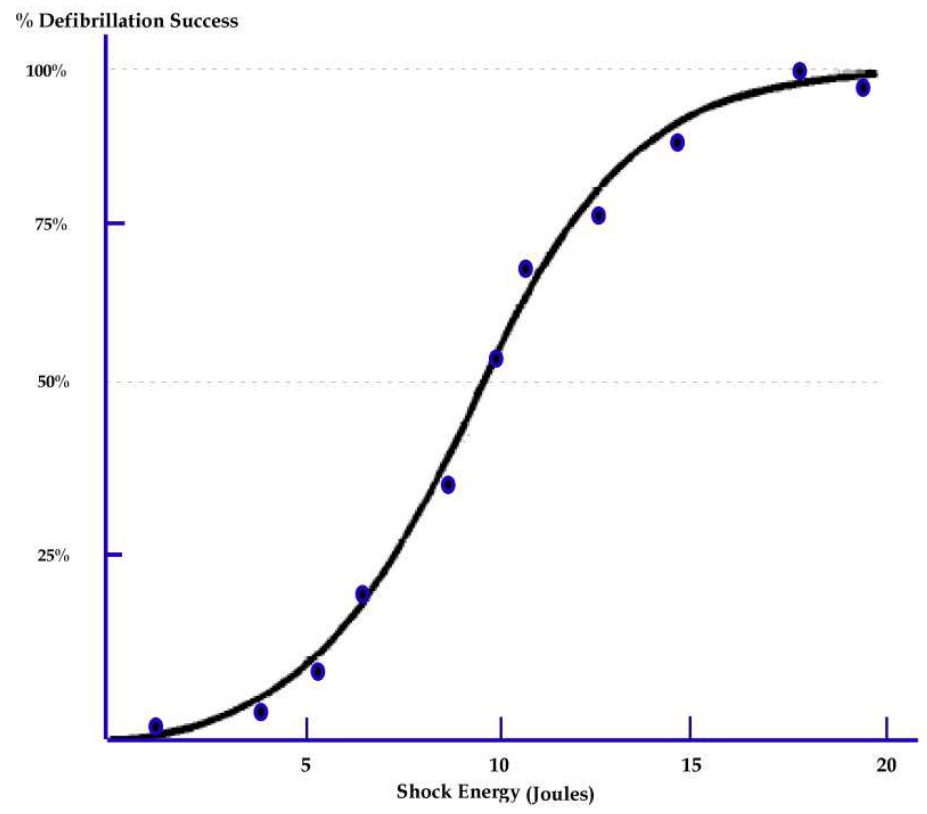

Fig. 2.1. The sigmoid-dose response curve showing nonlinear correlation between the defibrillation success and the delivered shock energy. This correlation is reproducible (see text). To achieve a higher defibrillation success the energy level has to be increased. There is a saturation level above which practically all the attempts will be successful. Per definition only $50 \%$ of the attempts will be defibrillated successfully at the threshold value. With a defibrillation energy twice higher than the threshold value the success rate is above $90 \%$. 


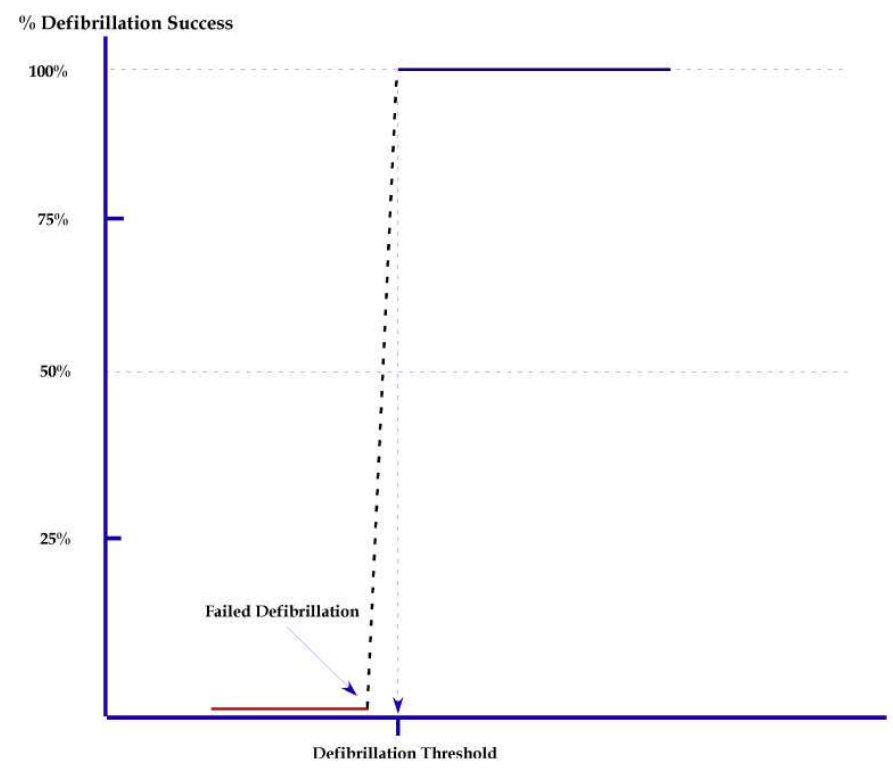

Fig. 2.2. The desired clinical defibrillation threshold testing. The immediately higher energy before the first failed attempt is considered the defibrillation threshold.

A.

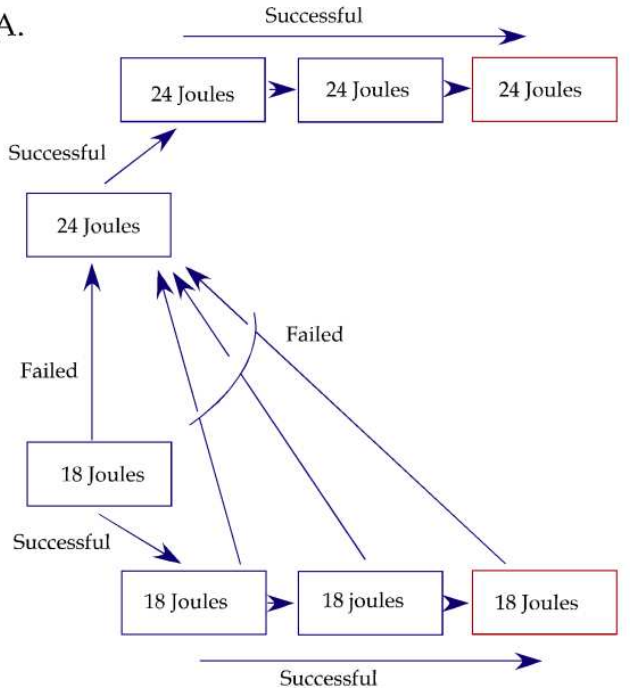

B.

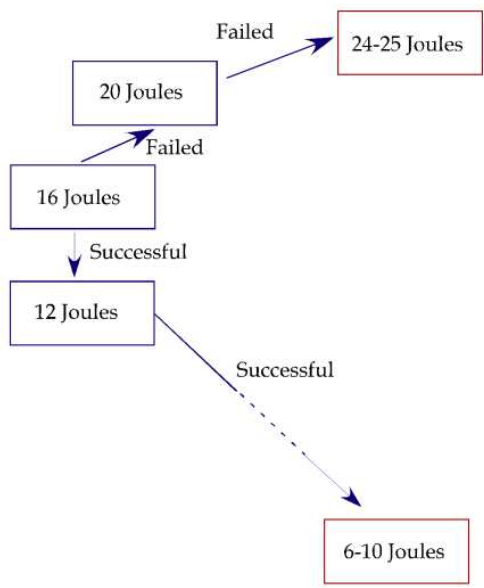

Fig. 2.3. Clinical protocols. A. Two-step fortified test. B. Multi-step test. For both test the last effective defibrillation energy is considered the DFT or best-predicted DFT (DFTdefibrillation threshold). If the highest acceptable energy is not effective, lead revision is recommended or addition of subcutaneous lead system. Today a single energy test is recommended (see text). Moreover, there is no unanimous agreement on the necessity of DFT testing at all (see text). 
When the more simplified defibrillation threshold testing (Figure 2.3B) was compared with the dose-response curve, the $\mathrm{ED}_{50}$ (the energy with $50 \%$ defibrillation success rate) was similar with the defibrillation threshold described above (Jones, 1991). Subsequently, more limited test (Figure 2.3A) was suggested and extensively used in clinical practice. This testing is based on induction of ventricular fibrillation and defibrillation with the same shock energy at least 3-4 times, consecutively (Figure 2.3A). If during one of the tests the defibrillation failed, a higher energy was tested, again 3-4 times. If the first energy was successful at all the attempts, it was accepted as the defibrillation threshold. If a higher energy was successful in all the consecutive tests, this energy was accepted as the defibrillation threshold, but only if a 10 Joules margin between this value and the device's maximal capacity was maintained. If the defibrillation with the highest acceptable energy was not successful, lead revision was required. Although this method may not offer the same accuracy as the dose-response curve or the limited defibrillation threshold testing (Figure 2.3B), it was reliable, predictive and the long-term survival of these patients was not affected (Rosenheck et al, 2009b). After implementation of the biphasic shock (Bardy et al, 1989) and the unipolar defibrillation system (Bardy et al et al, 1993) in the implantable defibrillators, the defibrillation threshold decreased much below the device capacity and testing with single defibrillation attempt is justified (Higgins et al, 2005). Moreover, as previously mentioned, the need of testing was seriously questioned (Viskin \& Rosso, 2009).

\subsection{Studies of the defibrillation threshold}

Although successful defibrillations were described in human subject already in the 1940's and 1950's, originally AC current (alternating current) was used for this purpose (Hooker et al, 1933; Beck et al, 1947; Zoll et al, 1956). Gurvich \& Yuniev performed in the mid 1930's experiments with DC (direct current) shock defibrillation (Gurvich \& Yuniev, 1947). However, this type of defibrillation has become popular only in the early 1960's when Schuder et al published their experiments with truncated direct current shock defibrillation and from then this waveform is used both for clinical and experimental defibrillations (Schuder et al, 1964).

Although, it was known for a long time that the success of defibrillation depends on the shock strength (Hooker et al, 1933), only after the introduction of DC shock defibrillation it has become possible to obtain the above described dose response curve. Different methods were used to increase the delivered energy. Schuder et al used constant-current system to evaluate the defibrillation efficacy and prolonging or shortening the pulse duration they achieved variation in the energy. Latter studies tested the defibrillation by increasing or decreasing the shock energy. In an experimental study, difference of $85 \pm 27 \%$ in the energy was found between $E_{80}$ and $E_{20}$, when $E_{80}$ was the energy level with $80 \%$ successful defibrillations and similarly $E_{20}$ represents the energy level with $20 \%$ successful defibrillations. This study definitely demonstrated the correlation between the shock amplitude and the success of defibrillation (Davy et al, 1987).

The defibrillation energy required for early defibrillation is much lower than after a prolonged episode. The defibrillation energy needed after a few cycles of ventricular

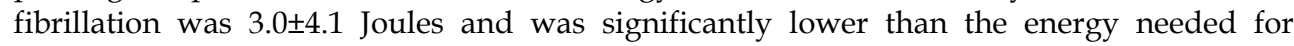
defibrillation after 10 seconds, which was 15.8 \pm 6.6 Joules (Strobel et al, 1998). Prolonged spontaneous or induced ventricular fibrillation, compared to short episodes, required a greater potential gradient for successful defibrillation and to achieve this gradient there was need of higher shock energy (Niemann et al, 2010). After 6 minutes of ventricular 
fibrillation, the first shock defibrillated the heart in $82 \%$ of the cases with 360 Joules biphasic shocks and only in $25 \%$ of the cases with 150 Joules biphasic shocks (Walcott et al, 2010). There are several clinical conditions, which require higher than usual energy for successful defibrillation: hypertrophic cardiomyopathy, acute ischemia, and several antiarrhythmic agents. The dose response curve will move rightward in a case of higher defibrillation threshold and to the left with lower defibrillation threshold (Figure 2.4). In the clinical evaluation, if the measured threshold will be higher, also the programmed energy has to be higher to achieve high defibrillation success rate.

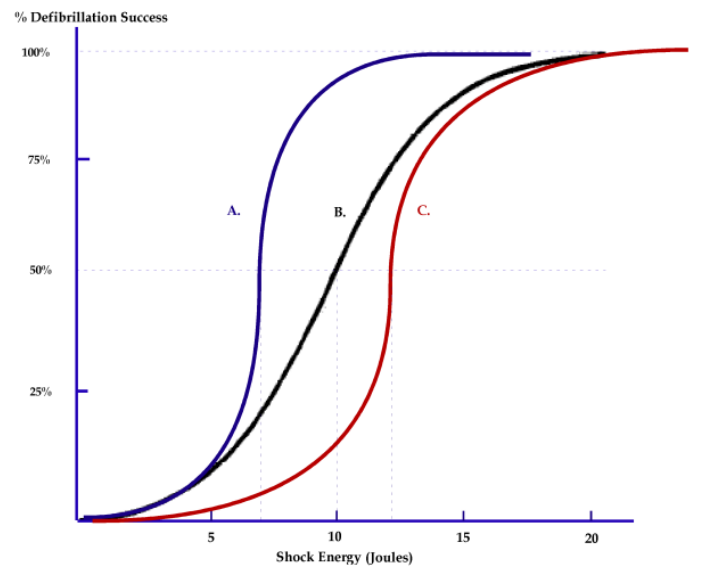

Fig. 2.4. The graph shows 3 dose response curves with different $\mathrm{ED}_{50}$ and different pattern. The clinical DFT will be lower in A and highest in C.

\subsection{The upper and lower limits of vulnerability}

The first requirement for a successful defibrillation is to terminate the fibrillatory activity in the myocardium. However, although the fibrillation may be terminated by the shock, the same shock may reinitiate the fibrillation. Early studies showed than a shock delivered during a vulnerable period may induce ventricular fibrillation (Wiggers \& Wegria, 1940). Figure 2.5 shows 2 examples of ventricular fibrillation induction with a shock delivered during the vulnerable period.
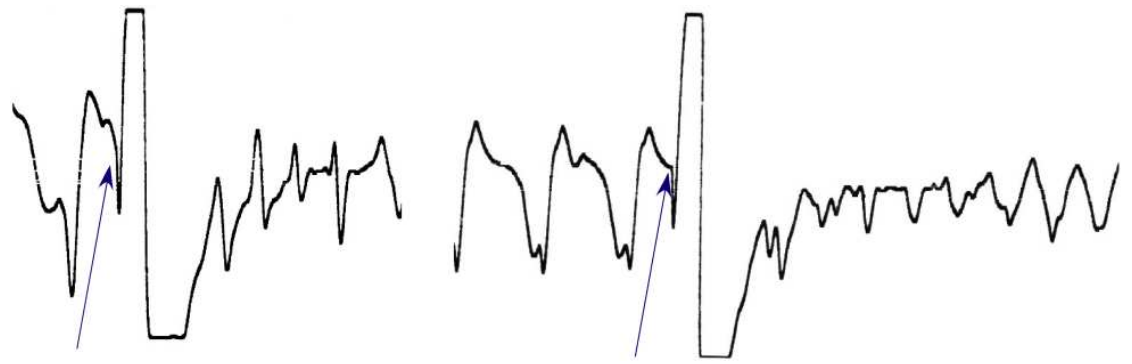

Fig. 2.5. Examples of 1.5 Joule shock induced VF. The shock was delivered early on the T wave (arrow). 
Chen at all demonstrated that a shock may induce ventricular fibrillation if it is higher than a certain energy called lower limit of vulnerability and is lower than the upper limit of vulnerability (Chen at al, 1986). Above the upper limit of vulnerability a shock, at any timing, will not induce fibrillation. Interestingly, there was a strong correlation between the upper limit of vulnerability and the defibrillation threshold (Chen at al, 1986; Schauerte, 1999). To avoid reinduction of fibrillation, the defibrillation shock has to be high enough to be above the upper limit of the vulnerability. During experimental defibrillations, different mapping methods resulted in disagreement on the process of defibrillation (Witkowski et al, 1990; Chen et al, 1990; Daubert et al, 1991; Dillon, 1992; Kwaku \& Dillon, 1996). However, experimental and simulation methods strongly suggest the re-induction model of defibrillation failure. This re-excitation is avoided if the shock energy is above the upper limit of the vulnerability. Adopted from the brady-pacing area, also defibrillation shocks may generate virtual electrodes. Experimental studies demonstrated that shock might induce virtual electrodes (Kinsley et al, 1994; Wikswo JP et al, 1995; Fast et al, 2002; Sharifov et al, 2004). The picture was completed with the computer simulation methods (Efimov et al, 1997; Efimov et al. 1998; Cheng et al, 1999; Efimov et al, 2000a; Efimov 2000b; Zemlin et al, 2006). Virtual electrode can create singularity points by closing an electrical circle through electrically conducting tissue. Above the upper limit of vulnerability, the shock amplitude is high enough to create opposing electrical poles enough far to impair closure of the circle. A second possibility is that a strong shock will prolong the refractoriness in a large mass of myocardium and this will prevents the closure of the circle. The third possibility is that a successful shock, although terminates the arrhythmia with the virtual electrode mechanism, but being strong enough, will abolish phase singularity point generated by the virtual electrode (Efimov et al, 200b; Trayanova N \& Eason, 2002; Trayanova N et al, 2006; Hayashi et al, 2007).

In conclusion, the shock amplitude may contribute to abolishing the fibrillating activity in a large myocardial mass and as a consequence all the fibrillation activity will be terminated. If the shock energy is above the upper limit of vulnerability re-excitation of the already recovered myocardial tissue will be prevented. At the tissue level, the shock abolishes the fibrillation activity; generated virtual electrodes-induced phase singularity, but if the shock is strong enough the singularities vanish before reentry wave generated by them will complete a full circle. As of today, the shock amplitude is the only parameter that can be controlled during defibrillation in both external and internal defibrillators.

\section{Shock location and clinical applications of shock vector}

Different electrode-pairs can record simultaneously both small and large ventricular fibrillation electrograms (Jones \& Klein, 1984). Figure 3.1 shows an example of ventricular fibrillation electrogram with simultaneously recording of low and high amplitude with different electrode-pairs.

Other experimental studies suggested that defibrillation synchronized to high amplitude ventricular fibrillation recording has a higher probability to be successful compared to shocks delivered on low amplitude recordings (Kuelz et al, 1994; Jones at al, 1997). Waveform analysis of ventricular fibrillation electrogram may predict the outcome of the defibrillation (Callaway \& Menegazzi, 2005). However, the reason may be the duration of the fibrillation. During early ventricular fibrillation the electrogram is course and the amplitude is high. The cycle length is also longer than during prolonged episode of ventricular fibrillation. As previously mentioned, the energy required to defibrillate the 


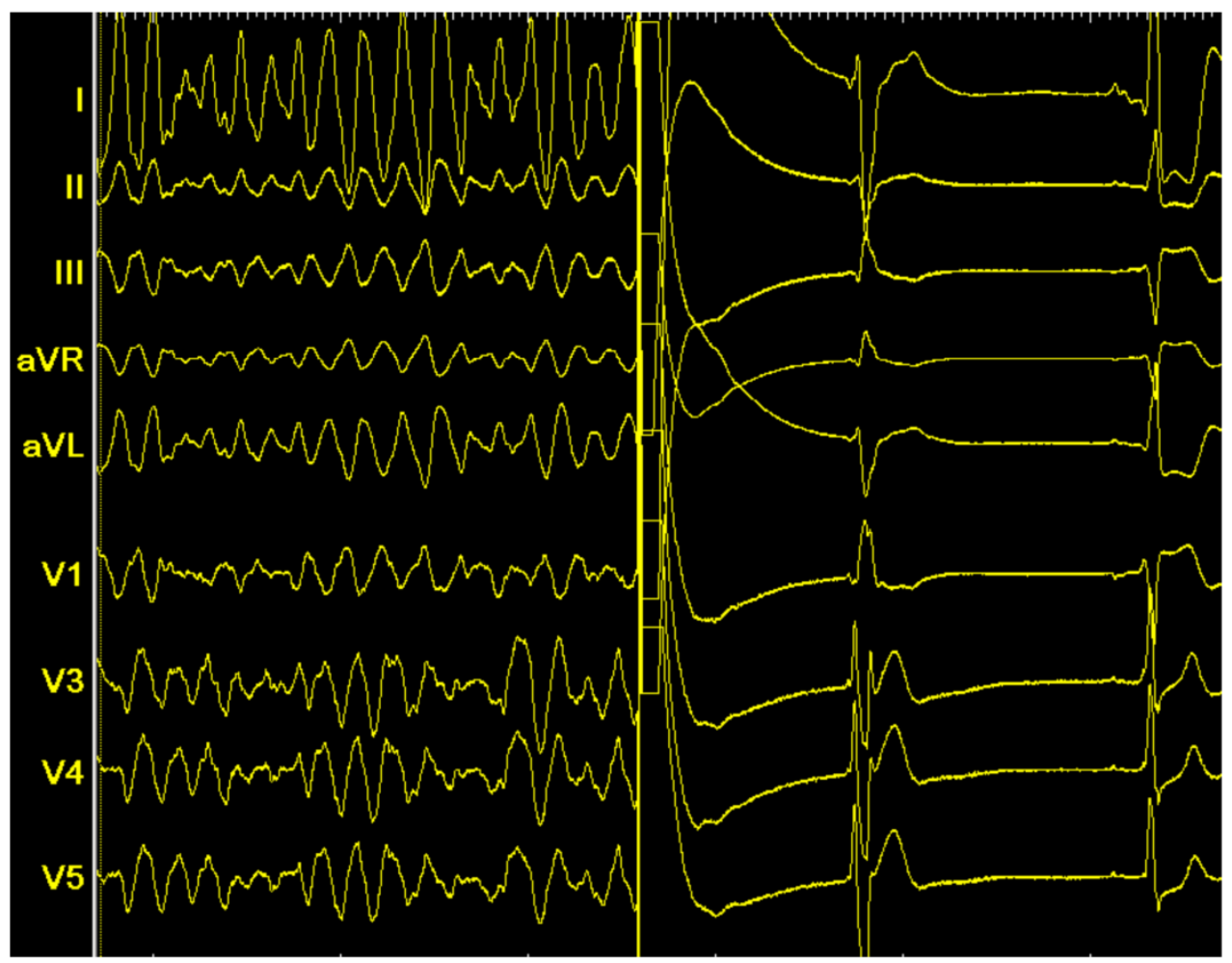

Fig. 3.1. Ventricular fibrillation electrogram showing simultaneously low and high amplitude recording in different leads. The shock terminates the fibrillation and sinus is regained. The amplitude in $\mathrm{L}_{1}$ is high and at the same time in AVR is low.

heart is much smaller during short duration ventricular fibrillation then after prolonged episodes (Section 2.2).

Brooks et al demonstrated that a shock delivered in a certain direction, chosen because there was high electrogram amplitude on it, was 5-9 times more likely to be successful than other direction without high electrogram amplitude (Brooks et al, 2009). In their study, two shock directions were used: orthogonal and lateral. Using the lateral vector, defibrillation with 30 Joules was more effective than the orthogonal vector, but the difference did not achieve statistical significance. With 50 Joules, in the lateral direction, the success rate was $68.3 \%(50.2-$ $81.1 \%)$ and in the orthogonal direction the success rate was only $18.9 \%(8.3-37.5 \%)$. This difference was statistically significant. When 100 Joules was used the success rate was high and similar with the two vectors, suggesting that a strong shock is successful in any direction (see Section 2.3).

In our study, performed in 20 patients (age 59 \pm 12 years, 16 patients with coronary artery disease, left ventricular ejection fraction $0.39 \pm 0.08$ ), during defibrillator implantation, 80 defibrillations were performed using monophasic shocks (Rosenheck et al, 2006). The defibrillation shock energy was in the defibrillation threshold zone or immediately below it. The ventricular fibrillation waveform amplitude was $9.5 \pm 7.7 \mathrm{mV}$ in the successful attempts 
and $6.1 \pm 4.4 \mathrm{mV}$ in the failed attempts $(\mathrm{p}=0.0318)$. The monphasic shock has two components on the surface electrogram. A third and large component belongs to the polarization effect. One component is in the same direction with the wavefront direction and the other component is in the opposite direction. We defined the component in the wavefront direction as component 1 and the other one as component 2. Component 1 was divided with component 2. The mean fraction was $0.9 \pm 2.2$ in the successful defibrillations and $3.2 \pm 5.6$ in the failed defibrillations ( $p=0.0006)$. This is suggesting that the combined shock vector is in the opposite direction to the last fibrillation waveform in the successful attempts and in the direction of the waveform in the failed attempts (Figure 3.2).

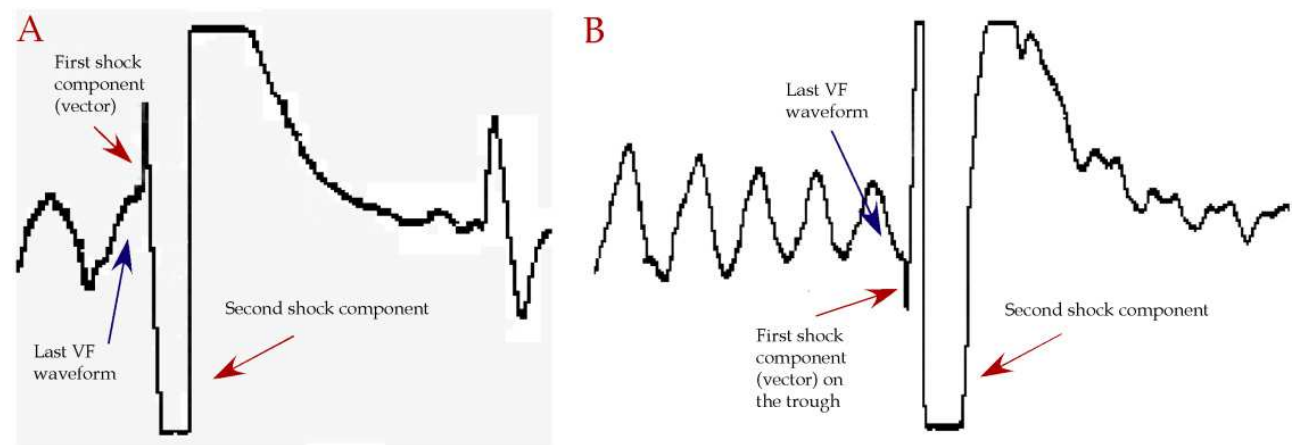

Fig. 3.2. Monophasic shock components and the wavefront direction. The first two components belong to the shock. The third component is the polarization. In picture A, successful defibrillation, the first component in the direction of the waveform (component 1 ) is significantly smaller then the component against the waveform (component 2) and the 1:2 $<1$. In picture $B$, failed defibrillation, the first component (component 2 ) is against the waveform direction and 1:2>1.

\section{Shock timing - Basic research}

As described in the Section 2.1, the success of defibrillation is correlated to the shock energy in a probabilistic mode, and is described by a dose-response curve. The immediate meaning of this non-linear function is that even at a low energy a small percent of attempts will be successful and during the same time a small percent of the defibrillation attempts at high energy may not be successful. The single logical reason is that the success of defibrillation, 
although it is possible only with strong shocks, it is also determined by the state of the tissue immediately before the shock.

In an isolated cell the shock will affect the membrane potential and the effect drops over the cell length. It is maximal at the site of the shock and minimal at the opposite site. This decay in the effect at the cellular level is still linear. The major effect is on the extracellular voltage and the effect on the membrane is the difference between the extracellular voltage changes versus the minimal change in the intracellular voltage. Two factors will determine the effect of a shock on the cellular membrane potential, the state of the cell at the moment of the shock and the strength of the stimulus (Drosdall et al, 2010).

At the level of a tissue strand, the effect of the shock will be much more complex. If a nonconducting obstacle will be on the way of the electrical field, which is usually the case, the shock will depolarize as expected the area before the obstacle and will hyperpolarize the area after the obstacle. Due to the difference in the polarity, a current flow will be generated through non-refractory tissue and in a larger three-dimensional tissue wedge fibrillation may be re-induced. A weak shock will have an almost linear effect when a stronger shock has a non-linear effect. Shock may induce also an asymmetric effect with non-equal negative and positive charges in membrane potential. Drosdall et al recently summarized this subject (Drosdall et al, 2010).

In the animal or human heart in situ, the ECG will be the only information on the tissue state during ventricular fibrillation. Therefore, synchronizing the shock to the ECG will affect the outcome of defibrillation. However, the early experiments had controversial data. First of all, the reason for this controversy is the type of ECG used. Using lead $\mathrm{L}_{2}$, for instance, will describe the electrical state of the myocardium from an angle on the inferiordiaphragmatic wall. This may not be the most representative area for the 3 dimensional tissues.

Other experimental studies evaluated the defibrillation outcome correlated to the amplitude and coarseness of the ECG recording. This may suggest that a large mass of myocardium was depolarized during the shock, meaning that the shock was delivered during the plateau of the action potential in a significant number of cells. However, it is well known that in different leads, during the fibrillation the amplitude may be even opposite. For this reason, not committed recording is needed. In the late studies with implantable defibrillators, the can-to-RV coil electrogram was used, or, as wee will see, in our human study anteroposterior patch-to-patch recording was used.

\subsection{Systematic review of the experimental studies}

Hsia and Mahmud for the first time evaluated if the random variation in the VF amplitude will affect the success of ventricular defibrillation (Hsia PW \& Mahmud R, 1990). The study was performed in 16 dogs. They recorded $\mathrm{L}_{2}$ electrograms and patch-to-patch recordings. The $50 \%$ success energy was determined and in the majority of the dogs it was below $500 \mathrm{~V}$ (except 2 dogs with 550 and $600 \mathrm{~V}$, respectively). A total of 82 attempts were successful and 95 failed. The mean defibrillation energy in the successful defibrillations was $6.1 \pm 1.4$ Joules compared to a similar energy in the failed attempts, $6.2 \pm 1.2$ Joules. The shock impedance was also similar and only the VF amplitude was significantly higher in the successful defibrillations compared to the failed attempts, $0.5 \pm 0.06 \mathrm{mV}$ versus $0.3 \pm 0.04 \mathrm{mV}$. The authors suggested that the cell may be in a relative refractory period during the shock and minimal differences in the shock timing may cause significant changes in the required 
effective defibrillation energy. A large electrogram may suggest a more advanced synchronization between the electrical sate of the fibrillating myocardial cells. Four examples of defibrillations are provided in the manuscript, two successful and two failed defibrillations. Although the amplitude in the successful examples was higher than in the failed attempts, in the successful defibrillations the shocks are delivered on the upslope and in the failed defibrillations the shocks are delivered on the downslope.

In a second study, moving average was computed on the ventricular fibrillation waveform (Kuelz et al, 1994). Lead $\mathrm{L}_{2}$ was used for recording. Averages for different length of moving points were calculated and windows from 1-16 provided the best discrimination between successful and failed defibrillation attempts ( $\mathrm{p}$ between 0.0007 to 0.0022 ). Above 16, the discriminating power of being course was less. Although these studies suggested the importance of the synchronization between the ventricular fibrillation waveform and the defibrillation shock, no difference between course and fine VF could be shown (Jonse DL \& Klein GJ, 1984). They also approved that fine and course ECG recording could be observed simultaneously in different limb leads or chest leads.

Hsia and his collogues, developed a method to detect peak higher than a threshold line (Hsia et al, 1996). If the shock was synchronized to these above-threshold peaks, the success rate was higher by $24 \%$. However, using this method the shock is delivered on the peak of the electrogram. This may suggest that timing might be more important than the recorded amplitude.

The next study was performed in 8 pigs and directly evaluated if shock timing may affect the defibrillation outcome (Hsu et al, 1997). There was no difference in the success between shocks delivered on high or low amplitude electrograms ( $48 \%$ in amplitudes $>1.3 \mathrm{mV}$ and $46 \%$ in amplitudes $<1.3 \mathrm{mV}$ ). However, shock delivered on the upslope resulted in $67 \%$ success rate and shocks delivered on the downslope resulted only in $39 \%$ success rate. The ICD morphology lead was used for recording, with the right ventricular coil as the cathode and the superior vena cava coil and sub-cutaneous array as the anode. Only course electrograms could be analyzed. The conclusion of this study was that timing to upslope, rather than to ECG amplitude is associated with defibrillation success.

Jones et al evaluated if shock synchronized to the action potential from low intensity area would predict favorable outcome of the defibrillation. This study was performed using 6 excised and Langendorff-perfused rabbit hearts. The VF inducing electrodes were placed in the right ventricle, or in the left ventricle. With this method, the basal septum was a lowintensity area and was chosen for monophasic action potential recording (Jones et al, 1997). The shocks were delivered early on the action potential, $5-40 \%$ from the start, or late, $40-$ $95 \%$. The energy with $50 \%$ chance of defibrillation was determined at both timing $\left(I_{50}\right)$. $I_{50}$ decreased by $17 \%$ by moving the shock from the late timing to the early timing, $1.48 \pm 0.47$ $\mathrm{mA}$ compared to $1.23 \pm 0.21 \mathrm{~mA}$. This $17 \%$ reduction in the current corresponds to $31 \%$ reduction in the energy. The dose-response curve of the early shocks was displaced to the left with a narrow standard deviation (see Figure 2.4 for explanation).

In a prospective study, Hsu at al developed software synchronizing the shock to four different parts of the VF waveform, as recorded with an ICD morphology electrogram (Hsu et al, 1998). The peak (maximal amplitude) and trough (minimum amplitude) were defined. The upslope was divided into three timings. Only high-amplitude recordings were used. The synchronized defibrillations were compared with random defibrillations. The doseresponse curve of probability-of-success versus shock intensity moved to left with the 
synchronized shock versus the random shocks (see Figure 2.4 for explanation). The $\mathrm{E}_{80}$ (energy with expected $80 \%$ success of defibrillation) decreased significantly from $27.1 \pm 2.5$ Joules to $22.9 \pm 1.8$ Joules. This study suggests, that shock synchronized to the upslope on the morphology electrogram of an implantable defibrillator, in an animal model, improved the defibrillation efficacy. Therefore, both the retrospective and the prospective experimental studies demonstrated that synchronizing the shock to the upslope of a noncommited electrogram, in this case the morphology electrogram, improves the defibrillation. Parallel, shocks synchronized to the early part of the action potential also improved the defibrillation. For this reason, the upslope may represent the early segment of the action potential and the downslope the late segment. All this studies evaluate the defibrillation in short induced episodes of ventricular fibrillation, not exciding 20 seconds and the relevance of their conclusions is limited.

\subsection{Defibrillation of prolonged episodes of ventricular fibrillation}

As of today, a new area in the world of defibrillation is evolving, the automatic external defibrillators. As opposed to the conventional external defibrillators the automatic defibrillators requires preprogramming of the energy, just like the implantable devices. The use of these external automatic defibrillators will be necessarily later than 10-15 seconds. Therefore, additional studies are needed to evaluate the importance of timing in prolonged episodes of ventricular fibrillation termination. Several studies evaluated the ventricular fibrillation electrogram amplitude spectral area (AMSA) and slope not to predict merely the defibrillation efficacy, but to predict the result of resuscitation (Indik et al, 2010; Povoas \& Bisera 2000). As previously mentioned (Section 3), the high waveform amplitude may suggest short duration ventricular fibrillation and not necessarily timing. Obviously the result of resuscitation will be significantly different if performed early than after prolonged episode of ventricular fibrillation. For this reason, further studies on the preshock electrograms in these prolonged episodes of ventricular fibrillation is still needed.

\section{Shock timing - Clinical data}

Based on the experimental data, we purposed to evaluate the importance of defibrillation shock timing in human subjects during defibrillator implantation or during later defibrillation evaluation. First of all, we were searching for a reproducible and not committed electrogram. As is evident in Figure 5.1 and 5.2 when the fibrillation is recorded simultaneously in different standard ECG leads, the recording may be very different in simultaneously recorded leads. If at a particular time, on $\mathrm{L}_{1}$, the recording is course, in lead $\mathrm{L}_{2}$ may be fine. The shock may be on the upslope on $\mathrm{L}_{3}$ and precordial leads, but on the downslope on $\mathrm{L}_{1}$ and $\mathrm{L}_{2}$. The late experimental studies have used the morphology lead ECG (between the ICD can and the RV defibrillation lead, or between the superior vena cava defibrillation coil and the right ventricular defibrillation coil). Our study was performed using two large surface patch electrodes with a general antero-posterior and supero-inferior axis. One of the patch-electrodes was placed on the right side of the chest and the second patch-electrode was placed on the left side of the back. This recording was not committed neither to the antero-posterior axis, nor superior-inferior axis, but was a more general recording combining both directions. Figure 5.2 shows defibrillation on 12-lead ECG and Figure 5.3 the patch-to-patch recording. 


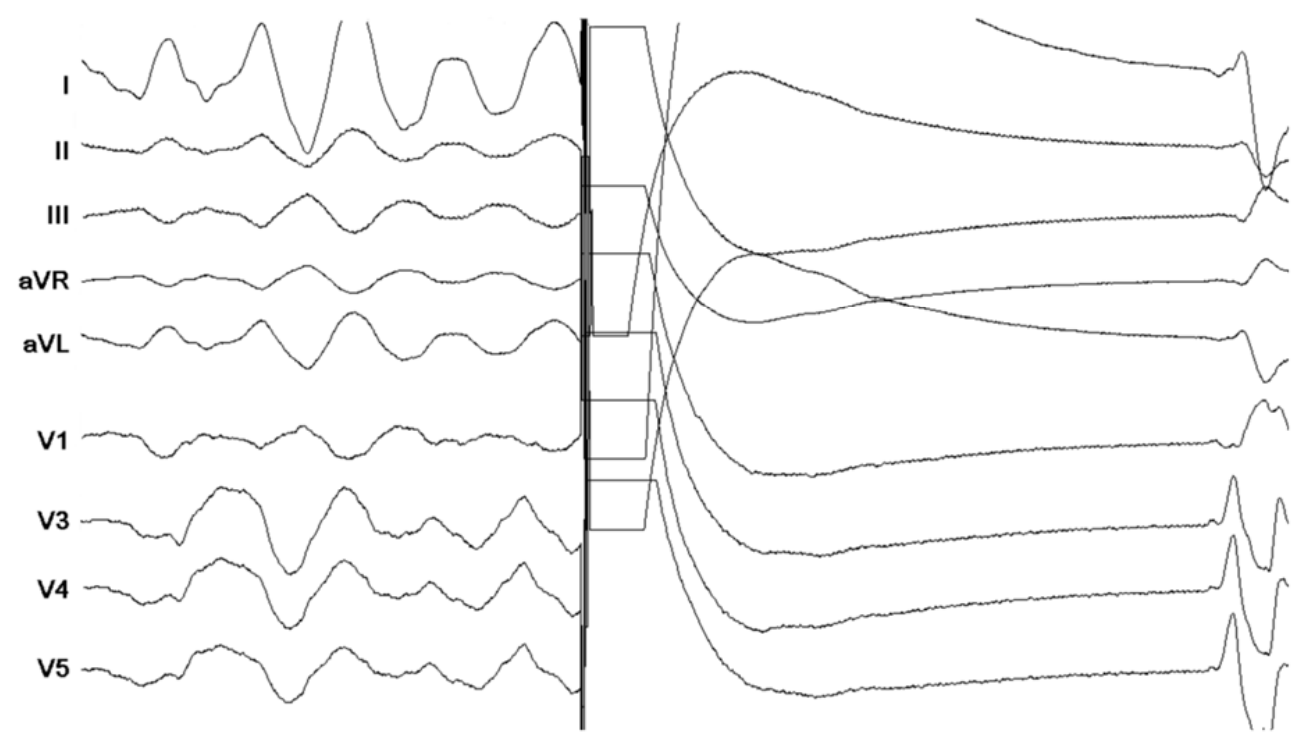

Fig. 5.1. Recording at $100 \mathrm{~mm} / \mathrm{sec}, 9$ lead ECG of ventricular fibrillation and defibrillation with implantable defibrillator, 14 Joules. The VF amplitude is high in lead $1, V_{3}$ and low in leads $2,3, \mathrm{~V}_{1}$. 


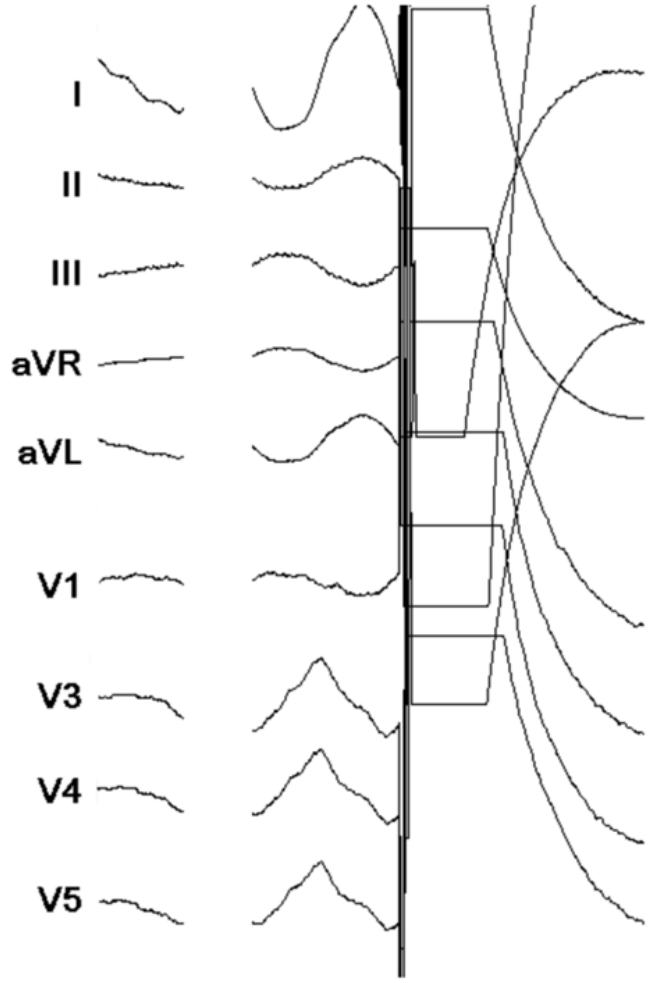

Fig. 5.2. The shock is delivered on the downslope in lead 1, 2, AVL and on upslope on leads $3, \mathrm{~V}_{1}, \mathrm{~V}_{3}, \mathrm{~V}_{4}, \mathrm{~V}_{5}$.

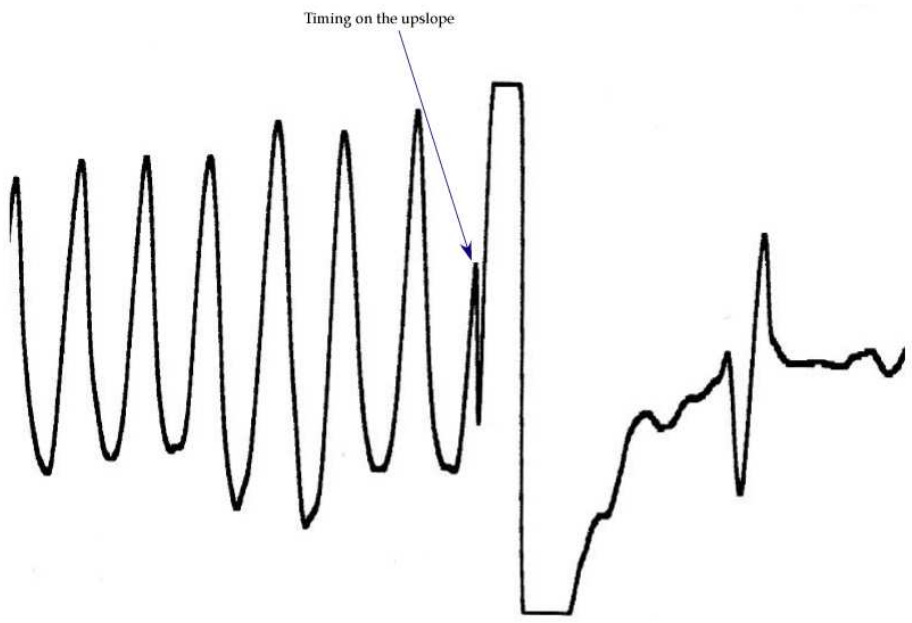

Fig. 5.3. A patch-to-patch recording with clear timing of the shock. 


\subsection{Shock timing studies in human hearts using biphasic shocks}

Our preliminary data was presented during an international symposium on cardiac arrhythmias ( $9^{\text {th }}$ Congress of the International Society for Holter and Noninvasive Electrocardiology and International Congress on Cardiac Pacing and Electrophysiology, Istanbul, Turkey September 23-27, 2000) and published in a monograph (Rosenheck et al, 2000). The last analysis was presented at the Heart Rhythm Association Annual Meeting in 2005 (Rosenheck \& Sharon, 2005). The study is still ongoing.

Figure 5.4 shows the definition of the shock timing on patch-to-patch recording.

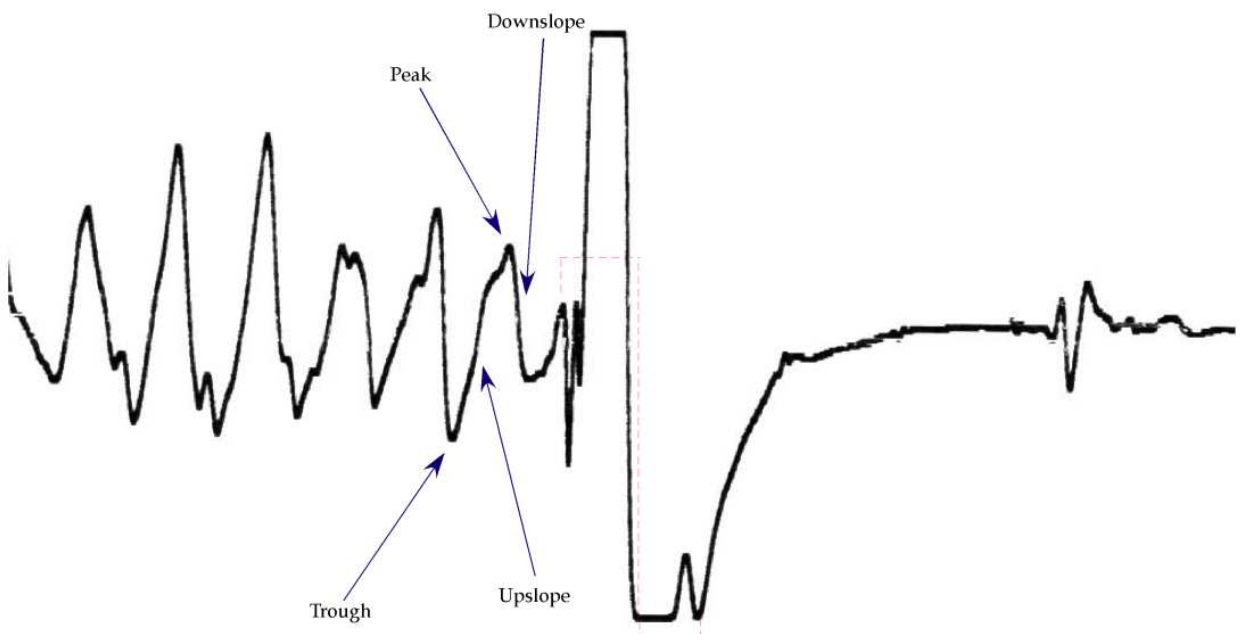

Fig. 5.4. Timing markers: Trough, peak, upslope and downslope. The first shock vector might be very complex like in this case. A single ventricular ectopic beat is evident on the last part of the shock recording (break stimulation).

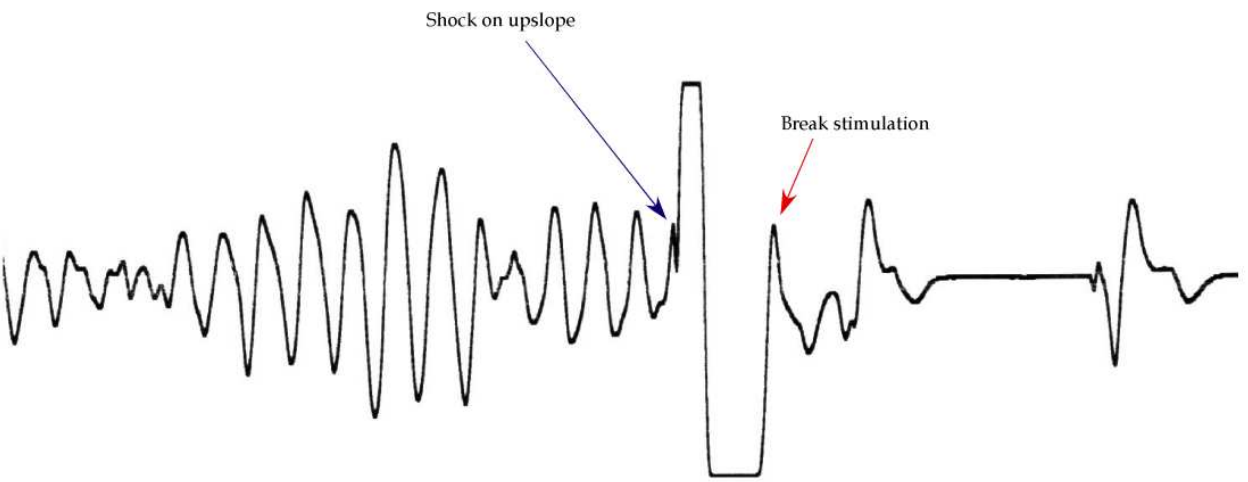

Fig. 5.5. Successful defibrillation with the shock delivered on the upslope. There is a limited post shock ventricular activity starting with the shock end and is suggestive of break stimulation without propagating it as result of prolonged refractoriness. 


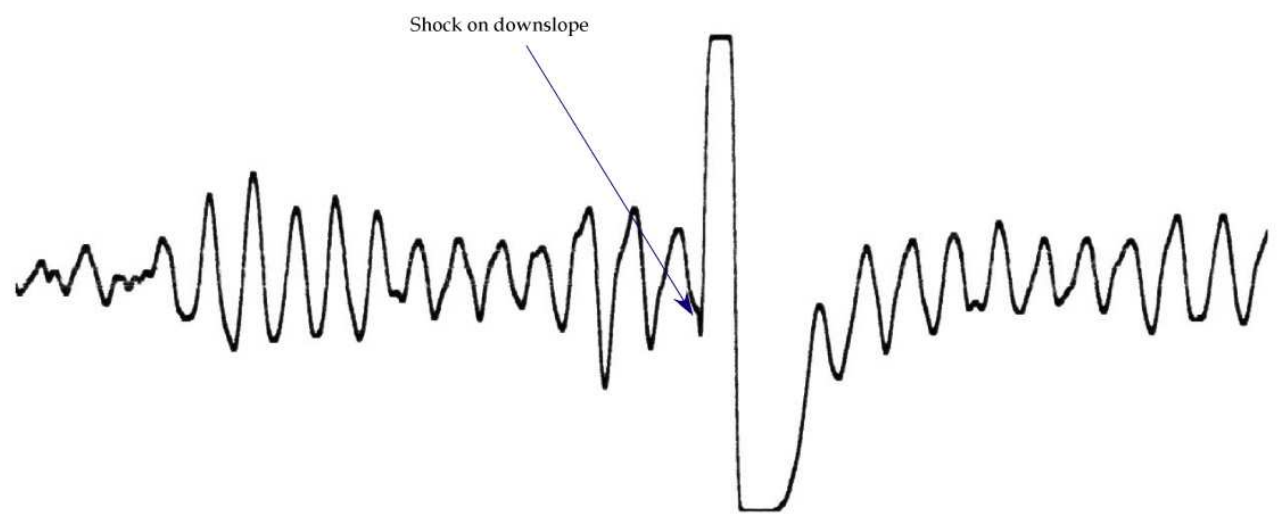

Fig. 5.6. Failed defibrillation with the shock delivered on the downslope. There is a slight difference between the preshock and post shock ventricular fibrillation waveform.

In the first report, 450 episodes of ventricular defibrillation were studied. The patch-to-patch ECG was recoded during ICD implantation and defibrillation evaluation. The electrograms were collected from 110 patients ( 88 male and 22 women). The mean age was $56 \pm 16$ years and the majority of the patients had coronary artery disease. The defibrillation effectiveness was evaluated using the Multi-step test (Figure 2.3B). Patients with low defibrillation thresholds were not necessarily studied until failed defibrillation was achieved and the test was discontinued if 6 Joule-shock defibrillated the heart. This was called the best-predicted DFT. Two groups were defined. One group, the outlying group, had either a very low defibrillation threshold or patients with high defibrillation threshold (between 18-25 Joules). Patients with defibrillation threshold $>25$ Joules were excluded. In the second group, the mid group, all the attempts were defibrillated with energy between 10-18 Joules. Ninetyfour episodes were in the outlying group and 356 in the mid group. In the outlying group, $74.1 \%$ of the shocks delivered on the upslope were successful versus $45 \%$ of the shocks on the downslope were successful $(p<0.01)$. In the mid group the success rate of the defibrillation on both upslope and downslope were similar and above $80 \%$. The conclusion was, that in the outlying group the efficacy was significantly higher on the upslope, because the narrower safety margin between the measured efficacy and the real DFT. In the mid group the safety margin was much wider and this relatively strong defibrillation shock may be effective in any way. Figure 5.5 shows a successful defibrillation on the upslope of the electrogram and Figure 5.6 shows a failed defibrillation on the downslope.

In the second study, 1374 additional episodes were included and studied. On the upslope, $87.3 \%$ of the defibrillations were successful and on the downslope $56.7 \%(p<0.0001$ and relative risk of failure on the downslope 1.442 [1.414 to 1.682]). In the best-predicted DFT zone $79.7 \%$ were on the upslope and in the lower energy group only 57.6 were on upslope $(\mathrm{p}<0.001)$. This study demonstrated strong association between the shock timing on upslope and success of defibrillation. The duration of the episodes was 8-10 seconds. The patch-topatch electrogram was coarse with intermittent short episodes of fine VF. The majority of the defibrillation shocks were on the large amplitude electrograms in both successful and failed attempts and the graphic analysis was easily performed. 


\subsection{Shock timing study in human heart using monophasic shock}

Additional information was obtained by analyzing patch-to-patch defibrillation electrograms using monophasic shocks and was presented at the World Congress of Cardiology 2006 (Rosenheck et al, 2006). Monophasic shocks were used in this study, to avoid more complex effect of the biphasic shocks, especially when the vectors are studied. In this study 96 defibrillation attempts with monophasic shocks were evaluated. The anteroposterior vector, the amplitude of VF electrogram and the shock timing were studied. Eighty episodes were defibrillated with energy at the clinical DFT or with immediately lower energy (50 at the DFT and 30 lower energy). In the successful defibrillations $84 \%$ were on the upslope and in the failed attempts only $37 \%$ were on the upslope $(p<0.01)$. As presented in Section 3, the electrogram amplitude and the shock vector direction had also significant effect on the success of defibrillation in these 20 patients (Figure 3.2). In addition to the importance of the timing, information on the underlying electrical activity and the interaction between the dominant VF vector and the shock vector were demonstrated (Section 3).

Although the conclusion after the experimental studies was that early shock might prolong the refractoriness and create conduction blocks in a critical mass of myocardium, more recent hypothesis on the mechanism of defibrillation may be used to explain our clinical results. It is accepted today that a shock has a non-uniform effect on the tissue. Both areas of depolarization and hyperpolarization are generated (Wikswo, 1994; Effimov et al, 1997). Obviously, the presence of both polarities, during the same time, will behave like an electrode, more precisely as a virtual electrode. The inversely polarized areas may be asymmetric, with one of the poles larger than the other. Internal nonconducting obstacles may facilitate this opposite polarization. If these poles are adjacent, a singularity point may be generated and a new spiral wave initiated (Efimov et al, 1998). Early shocks, when a large mass of myocardial cells are in their early phase of action potential, although may generate virtual electrode, but no excitable and conducting tissue will connect between the opposite polarized tissues. Slightly latter shocks may initiate the virtual electrodes and enough tissue may be already recovered to serve as electrical conducting tissue. Two adjacent polarized areas will provide the stimulation electrodes and non-refractory excitable tissue between them will provide the substrate for reentry.

The direction of the shock vector may also be explained with this new hypothesis. If the net shock vector is opposite to the main fibrillation waveform vector, it is less possibility to generate virtual electrode as the tissue is depolarized by the large wavefront. Moreover, a large mass of refractory myocardium will interfere with the conduction between the poles and the electrodes are abolished before the circle can be completed. It is also recently suggested that the main tissue responsible for the reinitiating the post-shock arrhythmia are the Purkinje Cells Network (Deo et al, 2009). These cells are densely distributed in the septum and the same area is also rich in singularity points (Trayanova, 2006). This may also contribute to the understanding of the importance of shock direction.

\section{Conclusions and future directions}

In addition to the contribution of the shock amplitude to the success of defibrillation, the shock orientation compared to the fibrillation waveform and shock timing is important for the defibrillation outcome. Experimental and clinical studies are supporting the importance of these three shock characteristics in the outcome of ventricular defibrillation. Understanding of 
these contributors to the defibrillation mechanism is important not only academically but also in the clinical practice. In the era of implantable defibrillators and automatic external defibrillators it is utmost important to understand the determinants of successful defibrillation. Implementing the timing and shock orientation in the defibrillation devices may improve the efficacy and the outcome of the defibrillation both for the implantable devices and nonprofessional operated external defibrillators.

\section{References}

Bardy GH, Ivey TD, Allen MD, Johnson G, Mehra R \& Green HL. (1989) A prospective evaluation of biphasic versus monophasic pulse on defibrillation efficacy in humans. J Am Coll Cardiol 14:728-733

Bardy GH, Johnson G, Poole JE at al. (1993) A simplified, single-lead unipolar transvenous cardioversion-defibrillation system. Circulation 88:543-547

Beck CS, Pritchard WH \& Feil HS. (1947) Ventricular fibrillation of long duration abolished by electric shock. JAMA 135:985-986

Brooks L, Zhang Y, Dendi R, Anderson RH, Zimmerman B \& Kerber RE. (2009) Selecting the transthoracic defibrillation shock direction vector based on VF amplitude improves shock success. J Cardiovasc Electrophysiol 20:1032-1038

Callaway CW \& Menegazzi JJ. Waveform analysis of ventricular fibrillation to predict defibrillation. (2005) Curr Opin Crit Care 11:192-199

Chen PS, Shibata N, Dixon EG, Martin RO \& Ideker RE. (1986) Comparison of the defibrillation threshold and the upper limit of ventricular vulnerability. Circulation 73:1022-1028

Chen PS, Wolf PD, Melnick SD, Danieley ND, Smith WM \& Ideker RE. (1990) Comparison of activation during ventricular fibrillation and following unsuccessful defibrillation shock in open-chest dogs. Circ Res 66:1544-1560

Cheng Y, Mowrey KA, Van Wagoner DR, Tchou PJ \& Efimov IR. (1999) Virtual electrode induced reexcitation. A mechanism of defibrillation. Circ Res 85:1056-1066

Dalal D, Nasir K, Bomma C, Prakasa K, Tandri H, Piccini J, Roguin A, Tichnell C, James C, Russell SD, Judge DP, Abraham T, Spevak PJ, Bluemke DA \& Calkins H. (2005) Arrhythmogenic right ventricular dysplasia. A United States experience. Circulation 112:3823-3832

Daubert JP, Frazier DW, Wolf PD, Franz MR, Smith WM \& Ideker RE. (1991) Response of relative refractory canine myocardium to monophasic and biphasic shock. Circulation 84:2522-2538

Daubert JP, ZarebaW, Rosero SZ, Budzikowski A, Robinson JL \& Moss AJ. (2007) Role of implantable cardioverter defibrillator therapy in patients with long QT syndrome. Am Heart J 153:S53-S58

Davy JM, Fain ES, Dorian P \& Winkle RA. (1987) The relationship between successful defibrillation and delivered energy in open-chest dogs: Reappraisal of the "defibrillation Threshold" concept. Am Heart J 113:77-84

Deakin CD, Nolan JP, Sunde K \&Koster RW. (2010) European resuscitation council guidelines for Resuscitation 2010 section 3: automatic external defibrillators, defibrillation cardioversion and pacing. Resuscitation 81:1293-1304

Deo M, Boylle P, Plank G \& Vigmond E. (2009) Arrhythmogenic mechanism of the Purkinje system during electrical shocks: a modeling study. Heart Rhythm 6:1782-1789 
Desai AS, Fang JC, Maisel WH \& Baughmann KL. (2004) Implantable cardioverter defibrillator for prevention of mortality in patients with nonischemic cardiomyopathy. A meta-analysis of randomized controlled trials. JAMA 292:28742879

Dillon SM. (1992) Synchronized repolarization after defibrillation shock. A possible component of the defibrillation process demonstrated by optical recording in rabbit heart. Circulation 85:1865-1878

Drosdall DJ, Fast VG \& Ideker RE. (2010) Mechanism of defibrillation. Annu Rev Bimed Eng 12:233-258

Efimov IR, Cheng YA, Biermann M, Van Wagoner DR, Magalev TN \& Tchou PJ. (1997) Transmembrane voltage changes produced by real and virtual electrodes during monophasic defibrillation shock delivered by an implantable electrode. J Cardiovasc Electrophysiol 8:1031-1045

Efimov IR, Cheng Y, Van Wagoner DR, Mazgalev T \& Tchou PJ. (1998) Virtual electrodeinduced phase singularity: a basic mechanism of defibrillation failure. Circ Res 82:918-925

Efimov IR, Aguel F, Cheng Y, Wollenzier B \& Trayanova N. (2000a) Virtual electrode depolarization in the far field: implications for external defibrillation. Am J Physiol Circ Physiol 279:H1055-H1070

Efimov IR, Cheng Y, Yamabouchi Y \& Tchou PJ. (2000b) Direct evidence of the role of virtual electrode-induced phase singularity in success and failure of defibrillation. J Cardiovasc Electrophysiol 2:861-868

Ezekowitz JA, Amstrong PW \& McAlister FA. (2003) Implantable cardioverter defibrillator in primary and secondary prevention: a systematic review of randomized, controlled trials. Ann Intern Med 138:445-452

Fast VG, Sharifov OF, Cheek ER, Newton JC \& Ideker RE. (2002) Intramural virtual electrodes during defibrillation shocks in left ventricular wall assessed by optical mapping of membrane potential. Circulation 106:1007-1014

Folke F, Gislason GH, Lippert FK, Nielsen SL, Weeke P, Hansen ML, Fosbol EL, Andersen SS, Rasmussen S, Schramm TK, Kober L \& Torp-Pedersen C. (2010) Differences between out-of-hospital cardiac arrest in residential and public locations and implications for public-access defibrillation. Circulation 122:623-630

Gurvich NL, \& Yuniev GS. Restoration of heart rhythm during fibrillation by a condenser discharge. (1947) Am Rev Soviet Med 4:252-256

Hayashi H, Lin SF \& Chen PS. (2007) Preshock phase singularity and the outcome of ventricular defibrillation. Heart Rhythm 4:927-934

Higgins S, Mann D, Calkins H, Estes MNA, Strickberger SA, Breiter D, Lang D \& Hahn S. (2005) One conversion of ventricular fibrillation is adequate for implantable cardioverter-defibrillator implant: An analysis from the Low Energy Safety Study (LESS). Heart Rhythm 2:117-122

Hooker DR, Kouwenhoven WB \& Langworthy OR. The effect of alternating currents on the heart. (1933) Am J Physiol 103:444-454

Hsia PW \& Mahmud R. (1990) Genesis of sigmoidal dose-response curve during defibrillation by random shocks: a theoretical model based on experimental evidence for a vulnerable window during ventricular fibrillation. Pacing Clin Electrophysiol 13:1326-1342 
Hsia PW, Freck S, Allen CA, Wise RM, Cohen NM \& Damiano RJ. (1996) A critical period of ventricular fibrillation more susceptible to defibrillate: real-time waveform analysis using single ECG lead. Pacing Clin Electrophysiol 19:418-430

Hsu W, Lin Y, Heil JE, Jones J \& Lang DJ. (1997) Effect of shock timing on defibrillation success. Pacing Clin Electrophysiol 20:153-157

Hsu W, Lin Y, Lang DJ \& Jones JL. (1998) Improved internal defibrillation success with shocks timed to morphology electrograms. Circulation 98:808-812

Huikuri HV, Castellanos A \& Myerburg RJ. (2001) Sudden cardiac death due to cardiac arrhythmias. N Engl J Med 345:1475-1482

Indik JH, Allen D, Shanmugasundaram M, Zuercher M, Hilwig RW, Berg RA \& Kern KB. (2010) Predictors of resuscitation in swine model of ischemic and nonischemic ventricular fibrillation cardiac arrest: Superiority of amplitude spectral area and slope to predict a return of spontaneous circulation when resuscitation efforts are prolonged. Crit Care Med 38:2352-2357

Jacobs I, Sunde K, Deakin CD, Hazinski MF, Kerber RE, Koster RW, Morrison LJ, Nolan JP, Sayre MR \& Defibrillation Chapter Collaborators. (2010) Part 6: Defibrillation: 2010 International consensus on cardiopulmonary resuscitation and emergency cardiovascular care science with treatment recommendation. Circulation 122:S325S337

Jonse DL \& Klein GJ. (1984) Ventricular fibrillation: the importance of being course? J Electrocardiol 17:393-400

Jones DL. Irish WD \& Klein GJ. (1991) Defibrillation Efficacy; Comparison of the defibrillation threshold versus dose-response curve determination. Circ Res 69:4551

Jones JL, Noe WA, Moulder C, Tovar OH, Hsu W \& Lin Y. (1997) Synchronized shock reduce defibrillation threshold. Proceedings-19th International ConferenceIEEE/EMBS 145-147

Kwaku KF \& Dillon SM. (1996) Shock-induced depolarization of refractory myocardium prevents wave -front propagation in defibrillation. Circ Res 79:957-973

Kinsley SB, Hill BC \& Ideker RE. (1994) Virtual electrode effect in myocardial fibers. Biophys J. 66:719-728

Kitamura T, Iwami T, Kawamura T, Nagao K, Tanaka H \& Hiraide A. (2010) Nationwide public-access defibrillation in Japan. N Engl J Med 362:994-1004

Knecht S, Sacher F, Wight M, Hocini M, Nogami A, Arentz T, Petit B, Franck R, De Chillou C, Lamaoson D, Farre J, Lavergne T, Verbeet T, Nault I, Matsou S, Leroux L. Weerasooriya R, Cauchemez B, Lellouche N, Derval N, Narayan SM, Jais P, Clementy J \& Haissahuerre M. (2009) Long-term follow-up of idiopathic ventricular fibrillation ablation: a multicenter study. J Am Coll Cardiol 54:522-528

Kuelz KW, Hsia PW, Wise RM, Mahmud R \& Damiano RJ. (1994) Integration of absolute ventricular fibrillation voltage with successful defibrillation. IEEE Transaction Biomed Eng 41:782-790

Maron BJ. (2000) Hypertrophic cardiomyopathy. A systematic review. JAMA 287:1308-1320

Niemann JT, Rosborough JP, Youngquist ST \& Shah AP. (2010) Transthoracic defibrillation potential gradients in a closed chest porcine model of prolonged spontaneous and electrical induced ventricular fibrillation. Resuscitation 81:447-480 
Povoas HP \& Bisera J. (2000) Electrocardiographic waveform analysis for predicting success of defibrillation. Crit Care Med 11 (Suppl.):N210-N211

Rea TD, Olsufka M, Bemis B, White L, Yin L, Becker L, Copass M, Eisenberg M \& Cobb L. (2010) A population-based investigation of public access defibrillation: role of emergency medical services care. Resuscitation 81:163-167

Rho RW, Page RL. (2011) Public access defibrillation. Heart Fail Clin A7:269-276

Rosenheck S, Leibowitz D \& Sharon Z. (2000) The effect of shock timing on the ventricular defibrillation in human hearts. In Oto A ed. New Trends in Electrocardiology. Monduzzi Editore, Bologna, Italy 107-112

Rosenheck S \& Sharon Z. (2005) Shock timing on the upslope of the fibrillation electrogram improves the defibrillation success. Heart Rhythm 2 (Supp):S85-S86

Rosenheck S, Weiss A \& Sharon Z. (2006) Shock timing, amplitude and underlying electrical activity determine success of defibrillation in humans using monophasic shocks. Eur Heart J 27 (suppl 1):468

Rosenheck S, Gorni S, Katz I, Rabin A, Shpoliansky U, Mandelbaum M \& Weiss AT. (2009a) Modified alternating current defibrillation-A new defibrillation technique. Europace 11:239-244

Rosenheck S, Sharon Z \& Weiss A. (2009b) Long-term follow-up of patients with relatively high effective defibrillation threshold during cardioverter defibrillator implantation with endocardial leads. Cardiology 112:107-113

Rosenheck S, Weiss A \& Sharon Z. (2010) Therapy success and survival in patients with valvular heart disease and Implantable Cardioverter Defibrillator. Int J Cardiol 144:103-104

Sacher F, Probst V, Iesaka Y, Jacon P, Laborderie J, Mizon-Gérard F, MaboP, Reuter S, Lamaison D, Takahashi Y, O'Neill MD, Garrigue S, Pierre B, Jaïs P, Pasquié JL, Hocini M, Salvador-Mazenq M, Nogami A, Amiel A, Defaye P, Bordachar P, BovedaS, Maury P, Klug D, Babuty D, Haïssaguerre M, Mansourati J, Clémenty J, \& Le Marec H. (2006) Outcome after implantation of cardioverter-defibrillator in patients with Brugada syndrome. A multicenter study. Circulation 114:2317-2324

Sharifov OF, Ideker RE \& Fast VG. (2004) High-resolution optical mapping of intramural virtual electrodes in porcine left ventricular wall. Cardiovasc Res 64:448-456

Schauerte PN, Ziegert K, Waldmann M, Schondube FA, Birkenhauer F, Mischke K, Grossmann M, Hanrath P \& Stelbrink C. (1999) Effect of biphasic shock duration on defibrillation threshold with different electrode configuration and phase 2capacitance. Prediction by upper-limit-of-vulnerability determination. Circulation 99:1516-1522

Silka MJ \& Bar-Cohen Y. (2006) Pacemaker and implantable cardioverter defibrillators in pediatric patients. Heart Rhythm 3:1360-1366

Schuder JC, Stoeckle H \& Dolan AM. (1664) Transthoracic ventricular defibrillation with square-wave stimuli: one-half cycle, one cycle, and multicycle waveforms. Circ Res 15:258-264

Strobel JS, Kenknight BH, Rollins DL, Smith WM \& Ideker RE. (1998) The effect of ventricular fibrillation duration and site of induction on the defibrillation threshold during early ventricular fibrillation. J Am Coll Cardiol 32:521-527

Trayanova N \& Eason J. (2002) Shock induced arrhythmogenesis in the myocardium. Chaos 12:962-971 
Trayanova N. (2006) Defibrillation of the heart: insights into mechanisms from modeling studies. Exp Physiol 91:323-337

Trayanova N, Plank G \& Rodriguez B. (2006) What we have learned from mathematical models of defibrillation and postshock arrhythmogenesis? Application of bidomaine simulation. Heart Rhythm 3:1232-1235

Viskin S \& Rosso R. (2008) The top 10 reasons to avoid defibrillation testing during ICD implantation. Heart Rhythm 5:391-393

Walcott GP, Melnick SB, Killingsworth CR \& Ideker RE. (2010) Comparison of low-energy versus high-energy biphasic defibrillation shocks following prolonged ventricular fibrillation. Prehospital Emergency Care 14:62-70

Wiggers CJ. (1940) The physiologic basis for cardiac resuscitation from ventricular fibrillation-methods for serial defibrillation. Am Heart J 20:413-422

WiggersCJ \& Wegria R. (1940) Ventricular fibrillation due to single localized induction and condenser shock applied during the vulnerable phase of the ventricular systole. Am Heart J 20:500-505

Wikswo JP. (1994) The complexity of cardiac cables: Virtual electrode effect. Biophysical J 66:551-553

Wikswo JP, Lin SF, Abbas RA. (1995) Virtual electrodes in cardiac tissue; a common mechanism for anodal and cathodal stimulation. Biophys J. 69:2195-2210

Winkle RA. (2010) The effectiveness and cost effectiveness of public-access defibrillation. Clin Cardiol 3:396-399

Witkowski FX, Penkoske PA \& Plonsey R. (1990) Mecahnism of cardiac defibrillation in open-chest dogs with unipolar DC-coupled simultaneous activation and shock potential recording. Circulation 82:244-260

Zemlin CW, Mironov S \& Pertsov AM. (2006) Near-threshold field stimulation; Intramural versus surface activity. Cardiovasc Res 69:98-106

Zipes DP, Fischer J, King RM, Nicoll A deB \& Jolly WW. (1975) Termination of ventricular fibrillation in dogs by depolarizing a critical amount of myocardium. Am J Cardiol 36:37-44

Zoll PM, Linenthal AJ, Gibson W, Paul MH \& Norman LR. (1956) Termination of ventricular fibrillation in man by externally applied electrical countershock. N Engl Med 254:727-732 


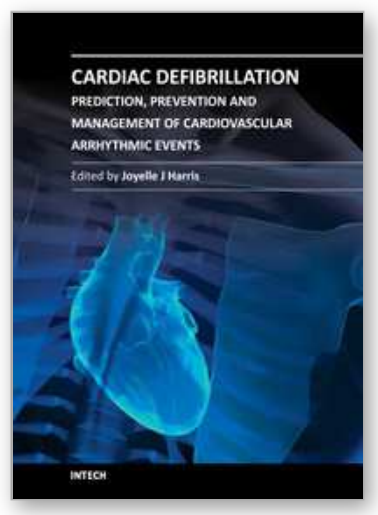

\section{Cardiac Defibrillation - Prediction, Prevention and Management of Cardiovascular Arrhythmic Events}

Edited by Dr. Joyelle Harris

ISBN 978-953-307-692-8

Hard cover, 176 pages

Publisher InTech

Published online 14, November, 2011

Published in print edition November, 2011

Millions of people throughout the world currently depend on appropriate, timely shocks from implantable cardioverter defibrillators (ICDs) to avoid sudden death due to cardiovascular malfunctions. Therefore, information regarding the use, applications, and clinical relevance of ICDs is imperative for expanding the body of knowledge used to prevent and manage fatal cardiovascular behavior. As such, the apt and timely research contained in this book will prove both relevant to current ICD usage and valuable in helping advance ICD technology. This book is divided into three comprehensive sections in order to cover several areas of ICD research. The first section introduces defibrillator technology, discusses determinants for successful defibrillation, and explores assessments of patients who receive defibrillation. The next section talks about predicting, preventing, and managing near catastrophic cardiovascular events, and research presented in the final section examine special cases in ICD patients and explore information that can be learned through clinical trial examinations of patients with defibrillators. Each chapter of this book will help answer critical questions about ICDs.

\section{How to reference}

In order to correctly reference this scholarly work, feel free to copy and paste the following:

Shimon Rosenheck (2011). Defibrillation Shock Amplitude, Location and Timing, Cardiac Defibrillation Prediction, Prevention and Management of Cardiovascular Arrhythmic Events, Dr. Joyelle Harris (Ed.), ISBN: 978-953-307-692-8, InTech, Available from: http://www.intechopen.com/books/cardiac-defibrillation-predictionprevention-and-management-of-cardiovascular-arrhythmic-events/defibrillation-shock-amplitude-location-andtiming

\section{INTECH}

open science | open minds

\section{InTech Europe}

University Campus STeP Ri

Slavka Krautzeka 83/A

51000 Rijeka, Croatia

Phone: +385 (51) 770447

Fax: +385 (51) 686166

www.intechopen.com

\section{InTech China}

Unit 405, Office Block, Hotel Equatorial Shanghai

No.65, Yan An Road (West), Shanghai, 200040, China

中国上海市延安西路65号上海国际贵都大饭店办公楼405单元

Phone: +86-21-62489820

Fax: $+86-21-62489821$ 
(C) 2011 The Author(s). Licensee IntechOpen. This is an open access article distributed under the terms of the Creative Commons Attribution 3.0 License, which permits unrestricted use, distribution, and reproduction in any medium, provided the original work is properly cited. 